\title{
TRANSFERENCIA DE LA PROPIEDAD EN LOS CONTRATOS DE COMPRA-VENTA INTERNACIONAL DE BIENES MUEBLES DETERMINADOS
}

\author{
TRANSFER OF PROPERTY IN CONTRACTS FOR THE \\ INTERNATIONAL SALE OF MOVABLE CERTAIN
}

\author{
Rose Mary Parra Rivera* \\ rosecatedra@hotmail.com
}

[RECEPCIÓN: MARZO DE 2015 / CONFORMIDAD: ABRIL DE 2015]

\begin{abstract}
RESUMEN
El presente artículo aborda el problema de cómo y en qué momento se determina el perfeccionamiento de la transferencia de la propiedad de los bienes muebles indicados en el contrato de compra-venta internacional. Para ello se fundamenta en la descripción del sistema de transferencia de propiedad en el derecho comparado, en las soluciones dadas al tema en varios de los regímenes pertenecientes a la familia del derecho civil. A la forma como varios códigos, incluido el nuestro, pertenecientes al sistema romano germánico, contemplan los efectos que se reconozca al contrato de compra-venta ya que, sobre el particular, existen dos posiciones: la primera, que le reconoce efectos reales (que sostienen que el contrato es suficiente) y, otra, que solo le reconoce efectos obligacionales (que requiere además de la celebración del contrato un acto adicional). Todo ello para buscar identificar en la práctica comercial internacional de dichas operaciones, el momento preciso en que se produce la traslación de la titularidad del derecho de propiedad de los bienes muebles determinados, saliendo del ámbito de dominio del exportador-vendedor (antiguo dueño) y simultáneamente, ingresando al ámbito de propiedad del importador-comprador (nuevo dueño), concluyéndose que el momento en el que se produce el perfeccionamiento de la propiedad es cuando se da "la puesta a disposición de la mercancía" (entrega ficta), que dependerá si la transacción se pactó con el transporte de las mercancías o sin éste.

Palabras clave: Transferencia de propiedad, contrato de compra-venta internacional, sistemas de transferencia, efectos del contrato de compra-venta, reglamentación uniforme del contrato de compraventa.
\end{abstract}

\section{ABSTRACT}

Article research addresses the problem of how and when it is determined that the improvement of the transfer of ownership of the property determined in the international sales contract. For it is based on the description of the property transfer system in comparative law in the solutions given to

\footnotetext{
Magíster en Derecho Comercial de la Universidad Nacional Mayor de San Marcos. Docente del curso de Negociación y Contratos Internacionales de la Facultad de Ciencias Administrativas de la Universidad Nacional Mayor de San Marcos. Juez del Segundo Juzgado Comercial.
} 
the subject in several of the schemes belonging to the civil law family. A how various codes including our belonging to the Roman-Germanic system include the effects to recognize the contract of sale, since this regard there are two (02) positions: the first, which recognizes real effects (holding that contract is sufficient), and another that only recognizes obligational effects (which also requires the contract an additional act.). All this to seek to identify international business practice of these operations, the precise time it occurs the transfer of ownership of the right of ownership of certain property, leaving the domain field of the exporter-seller (former owner) and simultaneously entering the field of property of the importer-buyer (new owner), concluding that the time when improvement occurs when the property is " given provision of the goods " (fictitious delivery), which depend if the transaction is deal with the transport of goods or without it.

Keywords: Transfer of Ownership, Contract of International Sales, Transfer Systems, effects of the contract of sale, uniform regulation of the sale contract.

\section{INTRODUCCIÓN}

La compra-venta internacional, más allá de sus implicancias de orden económico comerciales -de mayor importancia por cierto en el caso de la circulación de bienes-, descubre inmediatamente su connotación y naturaleza jurídica frente a los efectos que se derivan de ella porque el interés inmediato del comprador es adquirir la propiedad de manos del vendedor; es decir, le interesa cómo es que se produce la transferencia de la propiedad de las mercancías.

Siendo la compra-venta el mecanismo contractual por excelencia para la adquisición del derecho de dominio o propiedad, tenemos que en la compra-venta obligatoria se reconocen dos momentos definidos: el de la perfección del contrato y el de la transmisión del derecho de propiedad; el primero (título), solo generará la obligación del vendedor de transmitir la propiedad y la obligación a cargo del comprador de pagar el precio; y el segundo (modo) en el que se hace efectiva la transmisión de la propiedad a través de un segundo acto (la traditio) y por último explicar la naturaleza jurídica del acto que importa dicha transferencia, por cuanto en el contrato de compra-venta internacional la "puesta a disposición" de la mercadería equivale al modo (tradición ficta), de modo que producirá inmediatamente el efecto real de la transmisión de la propiedad.

Se analiza cómo se presenta el perfeccionamiento de la transferencia de la propiedad de los bienes muebles determinados en los contratos de compra-venta internacional, para ello estudiaremos la forma cómo ésta se encontraba regulada en el derecho romano, revisaremos codificación alemana, francesa e italiana así como codificaciones latinoamericanas, para luego analizar las modalidades de entrega que son empleadas en la práctica concluyendo con ello que en el contrato de compra-venta internacional es "el título" y la "puesta a disposición" de la mercancía a favor del comprador equivale a la "traditio", produciendo inmediatamente con la traditio el efecto real de la translación del derecho de propiedad en los bienes que conforman la mercancía adquirida.

\section{PLANTEAMIENTO DEL PROBLEMA}

\section{Situación del problema}

El contrato de compra-venta internacional es un instrumento jurídico que resulta valioso en las relaciones de comercio exterior, es así que las relaciones que se dan entre el vendedor (exportador) y el comprador (importador) se rigen por este contrato, no solo facilitando, sino también haciendo eficiente el tráfico fluido de intercambio de bienes y servicios; sin embargo, estas expresiones de voluntad deben sujetarse al marco legal de cada país y a las convenciones o acuerdos bilaterales o multilaterales según sea el caso, donde el perfeccionamiento de la transferencia de la propiedad en los contratos de compra-venta internacional de bienes muebles (mercancías) resulta relevante.

En tal sentido, es necesario establecer en qué momento se efectúa la transferencia de la propiedad de los bienes muebles en los contratos de compra-venta internacional, así como precisar la oportunidad en que se produce el efecto real de la transferencia de la propiedad y además conocer si las partes de la contratación necesariamente pueden compartir la misma posición, en caso le reconozca efectos real inmediato (teoría de la causa única) y en el otro le reconozca efecto real mediato (teoría de la doble causa), para ello es necesario identificar el momento u oportunidad de la transmisión de la propiedad en virtud de un contrato de 
compra-venta internacional, sin necesidad de tener que recurrir a ningún modo de adquisición, sino en las modalidades de entrega que son empleadas en la práctica comercial y buscando si existe reglas uniformes al respecto dentro de los tratados internacionales respecto al tema.

\section{Planteamiento del problema}

Se cree que en los contratos de compra-venta internacional de bienes muebles determinados, el perfeccionamiento de la transferencia de propiedad no se encuentra determinado recurriéndose a la legislación interna de cada uno de los sujetos que participan del contrato y dependiendo de cómo lo regulen, siendo necesario que se recurra a la práctica comercial internacional para determinar ello.

\section{Formulación del problema}

La investigación se puede formular mediante la siguiente interrogante general:

¿En qué momento se produce la transferencia de la propiedad de los bienes muebles determinados en los contratos de compra-venta internacional?

\section{Justificación y viabilidad}

Dentro del comercio exterior la compra-venta internacional es el contrato sobre el cual giran casi todas las importaciones y exportaciones de un país, siendo "internacional" no solo en razón de que en ella participan dos sujetos domiciliados en Estados diferentes (comprador-importador y vendedor-exportado), sino porque el tráfico de bienes y servicios se hace de un país a otro. El hecho que una mercadería de un productor nacional traspasa la frontera le da el carácter de tal y ante el interés inmediato del comprador de adquirir la propiedad de manos del vendedor resulta necesario saber cómo se produce la transferencia de la propiedad de las mercancías en dichos contratos internacionales. Dado que para determinar la transferencia de propiedad en la compraventa internacional, por lo menos se tendría la posibilidad de la aplicación de dos derechos internos a la operación comercial -dado su carácter internacional- y, más aún, ante las dos posibles soluciones distintas para un solo caso (en la medida que la ley nacional que resulte aplicable le reconozca al contrato efectos reales o efectos obligacionales), generando una inseguridad jurídica sobre el tema. Toda inseguridad jurídica genera trabas y un mayor costo en la operatividad comercial para quienes la efectúan, tales como generar controversias entre las partes y los operadores de dichas transacciones (porteadores, aseguradores, acreedores, autoridades de aduanas). Entonces surge la necesidad de establecer cómo y en qué momento se perfecciona la transferencia de propiedad de los bienes muebles determinados en la compra-venta internacional, contando con una norma uniforme supranacional que regule el tema de la transferencia de la propiedad en la compraventa internacional

\section{Objetivos de la investigación}

Determinar el momento en que se produce la transferencia de la propiedad de los bienes muebles determinados en los contratos de compra-venta internacional.

\section{Hipótesis de la investigación}

En la compra-venta internacional el perfeccionamiento de la transferencia de propiedad de los bienes muebles determinados se produce con la puesta a disposición de los mismos por parte del vendedor-exportador al compradorimportador.

\section{SISTEMA DE TRANSFERENCIA DE LA PROPIEDAD}

\section{Evolución histórica del vocablo "tradición"}

A partir del concepto de "transmisión" o "entrega", la palabra toma un significado preciso en materia jurídica: “entrega de una cosa”. Pero aún dentro del campo jurídico, el vocablo se emplea a veces con un significado más lato, y comprende la transferencia o transmisión de derechos, aunque no haya "entrega de la cosa" como vemos en la llamada "traditio brevi manu".

Esto no debe sorprendernos, pues como lo destaca Puig Brutau (1994), los hombres de derecho con frecuencia nos preocupamos por establecer los requisitos o condiciones que caracterizan una institución y, a reglón seguido, creamos excepciones que consideramos necesarias para el buen funcionamiento práctico de esa institución. Este fenómeno se produce en materia de posesión y de tradición, y lo veremos surgir a cada paso a medida que analicemos el tema.

La "traditio" aparece en el Derecho romano reemplazando a la "mancipatio" y a la "in iure 
cessio" como una forma más espiritualizada y práctica de transmitir la propiedad de la cosa. Es esa primera etapa la "entrega material" constituye un elemento esencial de la figura pero, a medida que transcurre el tiempo y evolucionan el pensamiento y las costumbres jurídicas, aparecen una serie de sucedáneos, en virtud de los cuáles se produce el efecto jurídico de transmitir la propiedad sin que sea menester la "entrega material" de la cosa y, por extensión, esos modos de transmisión de la propiedad van a quedar comprendidos dentro del significado genérico del vocablo "tradición" hasta que aparecen sistemas en los cuales se prescinde totalmente de la entrega de la cosa para producir la transferencia del derecho como el sistema del mero "consentimiento" del Código Civil Francés, o el de la "inscripción constitutiva” en un registro de tipo germánico.

Destacamos, entonces, que en una primera etapa la "tradición" era la "entrega material" de la cosa que producía como efecto la transferencia del derecho real de dominio; posteriormente se extiende a la entrega para la transmisión o constitución de otros derechos reales, para llegar a comprender, incluso, hipótesis en que la entrega tiene por finalidad la transmisión de derechos que no son reales, siendo indispensable para nuestro presente trabajo analizar desde la transmisión de derechos reales, como es la propiedad, existiendo teorías respecto a la transmisión de la propiedad.

\section{Teorías de la transmisión del derecho de la propiedad}

Cualquier tema relacionado a la propiedad, como es el referido a sus atributos y entre ellos el de enajenación o transferencia, esta ineludiblemente ligada al campo de los Derechos Reales al constituir el derecho de propiedad su máximo exponente; siendo precisamente ese carácter de derecho real (de la propiedad) que inmediatamente nos hace pensar en una situación jurídica susceptible de hacerse valer contra todos (erga omnes).

Así, refiriéndose a la obligación que impone el derecho real a la colectividad de respetar a su titular, se ha dicho acertada y objetivamente que "... la transmisión de un derecho real no solo atañe a las partes (enajenaste y adquiriente) sino que afecta también a la colectividad, que en adelante tendrá que respetar al nuevo titular. El Derecho en consecuencia, debe supervigilar y regular las modificaciones en la titularidad de los derechos reales en aras de garantizar su absolutividad tutelando en esa medida los intereses de la sociedad" (Boza 1986, p. 66).

En este contexto, encontramos que con relación a la transmisión del derecho de propiedad (bajo cualquier forma jurídica: compra-venta, donación o permuta) existen dos teorías: a) Teoría de la causa única (o transferencia "solo consensus") y b) Teoría de la doble causa (o teoría del título y el modo).

Ambas no se explican sino a través de los efectos que se les reconoce a los actos de transferencia de la propiedad; las mismas que son dos (Barchi 1992, p. 54): un efecto obligatorio que es propio e inmediato a todo acto jurídico, que es crear una relación jurídica (cuando no modificarla, regularla o extinguirla), y otro efecto real, que es propio y exclusivo de todo acto que tienen como función el transferir la titularidad del derecho de propiedad, consistente precisamente dicha transferencia y que puede tener carácter mediato.

Dependerá pues de la mediatez o inmediatez que se le reconozca a este efecto real para saber el Sistema adoptado por cada legislador, el de la causa única o el de la doble causa:

a) Teoría de la causa única (o también transferencia "solo consensus") que sostiene que el efecto real es inmediato, es decir que el mismo acto genera un doble efecto obligatorio (crear la relación obligatoria) y un efecto real (transmitir la titularidad del derecho de propiedad).

b) Teoría de la doble causa (o también teoría del título y del modo) que sostiene que el efecto real es mediato, esto es que no basta el acto que genera la relación obligatoria ("acto de obligación") sino que se requiere, además, otro acto a través del cual se produce el efecto real ("acto de disposición").

Refiere el Dr. Barchi, que en la teoría de la doble causa, el llamado "acto de obligación" es el título o causa remota (por ejemplo, el contrato de compra-venta); en tanto que el llamado "acto de disposición" es el modo o causa próxima por medio del cual éste derecho de propiedad sale del patrimonio del transmitente e ingresa al del adquirente (por 
ejemplo, la tradición, la inscripción); precisando, asimismo, que ambos -título y modo-son dos actos distintos pero dependientes en la medida que si bien cada uno tiene sus propios requisitos de validez y eficacia será necesario que el acto de obligación sea válido y eficaz para que el acto de disposición pueda producir su efecto (la transmisión del derecho de propiedad) (Barchi 1992, p. 54-55). Hay quienes sostienen, sin embargo, que la existencia de solo una causa jurídica relevante que da origen y justifica una adquisición es solo su fase ejecutiva, encontrando lo que se ha llamado "causa próxima" cuyo fundamento es la "causa remota” (Fernández 1994, p. 160).

No es objeto del presente trabajo entrar a discutir el punto de si es posible la existencia o no de la doble causa; bastándonos la clasificación para efectos prácticos en la medida que podamos reconocer a un sistema u otro cuando necesitemos determinar el momento en que se produjo la transferencia de la propiedad en un caso determinado.

3. Sistemas adoptados de la transmisión de la propiedad en la legislación nacional

El sistema adoptado por el legislador peruano es el Código Civil Peruano de 1984 pero no existe una opinión unánime en la doctrina nacional; para muchos “...nuestro Código acoge una modalidad mixta, según la cual se aplica el sistema de la unidad del contrato para la transferencia de los bienes inmuebles determinado y la teoría del título y el modo para la transferencia de los bienes muebles. Piensan otros que tratándose tanto de la transferencia de muebles como de inmuebles rige únicamente la teoría del título y el modo" (De la Puente y Lavalle año, p.12). De las lecturas consultadas podemos citar dentro del primer grupo a Hugo Flores Forno (año, p. 79) ${ }^{1}$ y Gastón Fernández Cruz (1994, p. 171)² en tanto que para el se- gundo grupo tenemos a Manuel de la Puente y Lavalle (año, p. 12) ${ }^{3}$ y a Bigio (1988).

Nuestro Código regula en sus artículos 947 y 949 -en el Libro de los Derechos Reales- la transferencia de la propiedad de los bienes muebles e inmuebles, respectivamente, señalando:

Art. 947.- La transferencia de la propiedad de una cosa mueble determinada se efectúa con la tradición a su acreedor, salvo disposición legal diferente.

Art. 949.- La sola obligación de enajenar un inmueble determinado hace al acreedor propietario de él, salvo disposición legal diferente o pacto en contrario.

Sin duda, el debate ha estado generalmente referido al sistema adoptado por nuestros legisladores a propósito de la transferencia de bienes inmuebles, tema sobre el que se ha escrito mucho pero en el que no vamos a incidir por no ser de relevancia para el presente trabajo; en cambio, no podemos decir lo mismo en materia de bienes muebles, puesto que teniendo claro el sistema adoptado por nuestro Código -o el de otros países, como veremos más adelante- podremos perfilar una posición sobre el momento en que operó la transferencia de la propiedad en las operaciones de compra-venta internacional, dependiendo -en cada caso- del derecho nacional que resulte aplicable.

Debemos, entonces señalar que en materia de bienes muebles, existe consenso en nuestro medio en que “...el Código adopta,...., la teoría de la doble causa, donde el modo es la tradición y, el título, un contrato cuya función es transferir propiedad (ejemplo, compra-venta, donación, permuta)" (Barchi 1992, p. 55-56).

En cuanto a la salvedad prevista por el citado artículo 947 recogemos la posición de que ésta “...debe entenderse referida a cierto tipo de

1 Ver por ejemplo Flores Forno cuando se refiere al sistema que nuestro ordenamiento jurídico ha establecido para la transmisión y constitución de los derechos reales y en particular del derecho de propiedad.

2 Ver por ejemplo, Fernandez Cruz cuando señala que “... creemos que a partir de la premisa errada de que el artículo 949 del Código Civil peruano consagra un sistema transmisivo de doble causa, se da pie a la existencia de interpretaciones extrañas y hasta peligrosas, tales como las de concebir a la tradición como el modo de transferencia de la propiedad inmueble en el Perú".

3 Ver por ejemplo, De la Puente y Lavalle para quien “... la introducción del artículo 949 del Código civil de 1984 no tiene significado de la inaplicación de la teoría del título y el modo a la transferencia de bienes inmuebles determinados, sino que por el contrario, dicha teoría es aplicable tanto para el caso de bienes muebles determinados como el de bienes inmuebles determinados". 
bienes de fácil identificación que están anotados en un Registro Público en el que se indica quién es su propietario, de tal suerte que para su transmisión requiere de un hecho distinto: la inscripción" (Boza 1986, p. 65).

\section{Sistemas adoptados de la transmisión de la propiedad en la legislación comparada}

Sistema adoptado por algunos formantes legislativos del sistema jurídico latinoamericano, español y francés, como ya lo señaláramos y así quedará establecido cuando tratemos aspectos de la compra-venta internacional resulta importante conocer cuáles son las legislaciones que han optado por uno u otro sistema, o ambos; así tenemos (Barchi 1992, p. 68):

\section{a) Códigos que adoptan la teoría de la doble causa:}

Código Civil de España (art. 609)4 . De acuerdo a lo opinado por José Bonet Correa, tenemos que si bien es cierto este Código Civil ha rehuido la transmisión de la propiedad por el solo consentimiento y exige la tradición, o sea, el cumplimiento del traspaso de la posesión de los artículos 609 y 109, también lo es que no ha de hacerse siempre de forma material, pues admite de una manera expresa la figura del constitutivo possesorio en los artículos 1462, segundo párrafo para los in- muebles; en el artículo 1463 para los muebles y en el 1464 par los bienes incorporales; ficciones simplificadoras que aparejan el desplazamiento posesorio por encima de toda apariencia de continuidad de la cosa en poder del vendedor (Sentencia del 09 de noviembre de 1971).

En el Código Civil de la República Argentina ${ }^{5}$ (art.574) ${ }^{6}$, de conformidad con lo dicho por Freitas tenemos que el principio de la tradición para la adquisición de la propiedad, dice: "Por la naturaleza de las cosa, por una simple operación lógica, por un sentimiento espontáneo de justicia, por el interés de la seguridad de las relaciones privadas a que se liga la prosperidad general, se comprende desde el primer momento que el derecho real debe manifestarse por otros caracteres, por otros signos que no sean los del derecho personal, y que esos signos deben ser tan visibles y tan públicos cuando sea posible. No se concibe que una sociedad esté obligada a respetar un derecho que no reconoce".

En materia de obligaciones de dar cosas", con el fin "de transferir solamente el uso o la tenencia" y, de manera concordante, cuando al tratar de la simple tenencia que es típica del ejercicio de derechos meramente personales), dispone que "solo adquiere por la tradición” (artículo $2460^{7} \mathrm{del}$ Código Civil argentino).

4 Código Civil Español: La propiedad se adquiere por ocupación. Real Decreto 24/07/1889. Real Orden de 29 de julio de 1889. "La propiedad y los demás derechos sobre los bienes se adquieren y transmiten por la ley, por donación, por sucesión testada o intestada, y por consecuencias de ciertos contratos mediante tradición. Puede también adquirirse por medio de la prescripción." Art. 1095.- "El acreedor tiene derecho a los frutos de la cosa desde que nace la obligación de entregarla. Sin embargo, no adquiere derecho real sobre ella hasta que le haya sido entregada".

5 El Código Civil de la República Argentina Ley No 340.- El Senado y Cámara de Diputados de la Nación Argentina, reunidos en Congreso, sancionan con fuerza de ley:

Art. $1^{\circ}$ El Código Civil redactado por el doctor Dalmacio Vélez Sársfield se observará como ley en la República Argentina desde el 1 de enero de 1871.

Art. $2^{\circ}$ La Suprema Corte de Justicia y Tribunales Federales de la Nación darán cuenta al Ministro de Justicia, en un informe anual, de las dudas y dificultades que ofreciere en la práctica, la aplicación del código, así como de los vacíos que encontrasen en sus disposiciones para presentarlas oportunamente al Congreso.

Art. $3^{\circ}$ El Poder Ejecutivo recabará de los Tribunales de Provincia, por conducto de los respectivos Gobiernos, iguales informes para los fines del artículo anterior.

Art. $4^{\circ}$ Autorízase al Poder Ejecutivo para hacer los gastos que demande la impresión del Código Civil, debiendo solo tenerse por auténticas las ediciones oficiales.

Art. $5^{\circ}$ Comuníquese al P.E. - Dada en la sala de sesiones del Congreso en Buenos Aires, a 25 de Setiembre de 1869. - ADOLFO ALSINA - Carlos M. Saravia, Secretario del Senado. - MANUEL QUINTANA - Ramón B. Muñiz, Secretario de la Cámara de DD. Departamento de Justicia - Buenos Aires, Setiembre 29 de 1869. - Téngase por ley, comuníquese, publíquese e insértese en el Registro Nacional. - SARMIENTO - N. Avellaneda.

6 Título VII De las obligaciones de dar

Cap. I - De las obligaciones de dar cosas ciertas

Código Civil Argentino Artículo 574.- "La obligación de dar, es la que tiene por objeto la entrega de una cosa, muebles o inmueble, con el fin de constituir sobre ella derechos reales, o de transferir solamente el uso o la tenencia, o de restituirla a su dueño".

7 Título II De la Posesión y de la Tradición para adquirirla

Cap. VI - De la simple tenencia de las cosas

Artículo 2460.- La simple tenencia de las cosas por voluntad del poseedor, o del simple tenedor, solo se adquiere por la tradición, bastando la entrega de la cosa sin necesidad de formalidad alguna. 
Código Civil de Ecuador (artículos 622 y 705) ${ }^{8}$, las disposiciones de este Código Civil, en el Título VI “DE LA TRADICIÓN" del Libro II, contempla integrándose a la familia de los códigos que tomaron como modelo el Código de Chile, dedicando un título íntegro que comprende desde los artículos 705 y 733 a la tradición, dentro de los cuales en los artículos 705 y 733 reproducen textualmente los textos de los artículos 670 y 699 del Código Chileno. Por otro lado el artículo 721 es correspondencia del artículo 686 del Código Chileno, con ligeras variantes.

Código Civil de la República de Chile (artículos 670, 686 y 699) ${ }^{9}$. Este Código tiene dedicado a la tradición un título completo que inicia en el artículo 670 y termina en el artículo 699; de sus disposiciones se desprende la adopción de la teoría de la doble causa.

Código Civil de Colombia (artículos 673 y $740)^{10}$, En el se reproduce las normas del Código Chileno, también tomando la teoría de la doble causa, pero dentro de sus disposiciones notamos una ligera variante en la redacción del artículo 756.

\section{b) Códigos que adoptan la teoría de la causa única.}

En estos formantes legislativos que a continuación detallamos se establece que la propiedad o el derecho se adquieren y transmiten por el consentimiento, entre ellos tenemos los siguientes:

Código Civil de Venezuela (artículo 796) ${ }^{11}$,

Código Civil de Italia (artículos 588 y 670) ${ }^{12}$,

Código Civil de la República de Bolivia (artículos 110 y 521$)^{13}$.

c) Códigos que adoptan ambas teorías

Entre los formantes legislativos que se considera que han adoptado por ambas teorías tenemos a los siguientes:

- Código Civil de Brasil (inmuebles artículo 530 y muebles artículo 620$)^{14}$,

8 El Código Civil de Ecuador integra la familia de los códigos que tomaron como modelo el Código de Chile, dedicando un título integro que comprende los artículos 705 a 733 a la tradición, el primero y el último (705 y 733) reproducen textualmente los textos de los artículos 670 y 699 de los Chilenos. El 721 corresponde al 686, con ligeras variantes y dice: "Se efectuará la tradición del dominio de bienes raíces por la inscripción del título en el libro correspondiente del Registro de la Propiedad..."

9 El Código Chileno tiene un título integro que dedica a la Tradición, iniciando en el artículo 670 hasta el 699; de los cuales extractaremos tres de ellos que consideramos importantes siendo el artículo 670.- "la Tradición es un modo de adquirir el dominio de las cosas y consiste en la entrega que el dueño hace de ellas a otro, habiendo por una parte la facultad e intención de transferir el dominio, y por otra la capacidad e intención de adquirirlo. Lo que se dice del dominio se extiende a todos los otros derechos reales.”; artículo 686.- "Se efectuará la tradición del dominio de los bienes raíces por la inscripción del título en el Registro del Conservador..."; Artículo 699.- "La tradición de los derechos personales que un individuo cede a otro se verifica por la entrega del título hecha por el cedente al cesionario."

10 Código Civil de Colombia, artículo 740.- "La Tradición es un modo de adquirir el dominio de las cosas y consiste en la entrega que el dueño hace de ellas a otro, habiendo por una parte la facultad e intención de transferir el dominio, y por otra la capacidad e intención de adquirirlo. Lo que se dice del dominio se extiende a todos los otros derechos reales".

11 El Código Civil de Venezuela, artículo 796 dispone que "La propiedad se adquiere por la ocupación. La propiedad y demás derechos se adquieren y transmiten por la Ley, por sucesión, por efecto de los contratos. Pueden también adquirirse por medio de la prescripción".

12 El Código Civil Italiano, artículo 1376.- Contrato con efectos reales.- En los contratos que tengan por objeto la transferencia de la propiedad de una cosa determinada, la constitución o la transferencia de un derecho real o la transferencia de otro derecho, la propiedad o el derecho se transmiten y se adquieren por efecto de consentimiento de las partes legítimamente manifestado".

13 El Código Civil Boliviano.- El artículo 521: "En los contratos que tienen por objeto la transferencia de la propiedad de una cosa determinada o de cualquier derecho real, o la constitución de un derecho real, la transferencia o la constitución tiene lugar por efecto del consentimiento, salvo el requisito de la forma en los casos exigibles".

El artículo 110: "La propiedad se adquiere por ocupación, uso, por efecto del contrato, por sucesión mortis causa, por poseer de buena fe, y por las otras ley”.

14 El Código Brasileño dispone en la Secao I Da Aquisicao de Propiedad Imóvel en el artículo 530 - “Adquire-se a propiedade imóvel:

pela transcricao do titulo de transferencia no Registro de Imóvel;

- pela acessao;

- pelo usucapido

-pelo diriito hereditário “; y

En el Secao V Da Tradicao, en el artículo 620 - "O dominio das coisas nao se transfere pelos contratos antes da tradicao. Mas esta se subentende, quando o transmitente continua a possuir pelo constituto possessória”. 
- Código Civil de la República de Paraguay (inmuebles artículo 1966 y 1968 - muebles artículo $2088)^{15}$.

\section{LA "TRADICIÓN" COMO MODO CONSTITUTIVO DE LA TRANSFERENCIA DE LA PROPIEDAD DE BIENES MUEBLES}

Todo lo expuesto en los puntos precedentes han tenido por objeto explicar cómo y por qué participamos de la posición de que tratándose de bienes muebles la transmisión de la titularidad del derecho de propiedad (enajenación) exige cómo elemento indispensable "la tradición"; siendo propósito de este parte del trabajo, determinar los alcances de dicho concepto, de modo que nos sea útil -cuando nos refiramos a la compra-venta internacional regulada por la Convención de las Naciones Unidas sobre los Contratos de Compraventa Internacional de Mercaderías, que el Perú se adhirió- para comprender en qué supuestos nos encontramos frente a una tradición.

Al margen de la función publicitaria que se suele atribuir a "la tradición" -y que justificaría la opción del legislador (nacional o extranjero) de haber adoptado "la tradición" como el modo de la traslación de dominio- ${ }^{16}$ (Boza 1987, p. 59 y Moisset de Espanés 2004) vamos más bien a precisar los supuestos en los que se verifica la tradición y, en consecuencia, la transmisión del derecho de propiedad de un bien mueble determinado.

\section{Significado de la tradición}

Comencemos por señalar que, desde el punto de vista etimológico, la palabra "tradición" proviene del latín "tradere", que significa "transmitir".

Centrándonos en el ámbito jurídico, Moisset de Espanés (2004, p. 31) nos dirá que el concepto de "transmisión" o "entrega" toma un significado más preciso: "entrega de una cosa"; aunque, se emplee a veces con un significado más lato, comprendiendo la transferencia o transmisión de derechos, aunque no haya "entrega de la cosa" como es el caso de la "traditio brevi manu".

Esto último, responde sin duda a una evolución en el tiempo, puesto que como se indicó con anterioridad -cuando nos hemos referido a la compra-venta en el derecho romano- la "traditio" como modo de transmitir la propiedad de un bien, en un primer momento estaba referida específicamente a la "entrega material”, pero posteriormente como respuesta al desarrollo y complejidad de las prácticas en el tráfico comercial, se producirá el efecto jurídico de transferencia de la propiedad sin que se verifique una entrega material, suponiendo entonces reconocer otros modos de transferencia que -para dicho efecto- se entenderán como "tradición".

\section{Naturaleza jurídica de la tradición}

La "tradición", entendida como el modo de transferir la propiedad ${ }^{17}$, se torna relevante para el Derecho precisamente por los efectos jurídicos que supone; entonces, sobre la base de lo anotado en cuanto al carácter obligacional del contrato en general (ver punto 1.3.5), en consecuencia del contrato de compraventa, debemos señalar que compartimos la tesis de quienes atribuyen a la "traditio" la naturaleza del pago.

Moisset de Espanés lo explica: cuando el dueño o propietario de una cosa desea transferírsela a otra persona (que será el nuevo dueño), lo primero que hace es crear una obligación a través de un contrato (título o causa eficiente de la obligación). En esta etapa nace la obligación que pesa sobre el dueño (deudor), de transmitir al adquirente (acreedor) el derecho de dominio sobre la cosa; donde deudor y acreedor se encuentran unidos por un vínculo o relación obligacional. Luego, hay una segunda etapa

15 El Código Civil Paraguayo.- artículo 1968.- “La propiedad de bienes inmuebles se trasmite por contrato. Los títulos traslativos están sujetos a la toma de razón en el Registro de inmuebles para que se produzcan efectos respecto a terceros".

Artículo 2061.- "Las cosas muebles podrán adquirirse por contratos traslativos de propiedad, conforme a las disposiciones de éste Código".

16 Así por ejemplo, se atribuye a la "traditio" una función de publicidad; donde aquella es entendida como el traspaso de la posesión directa de manera exclusiva en favor del adquirente. "La posesión directa con signo externo (y no la entrega, que generalmente permanece oculta a la colectividad) es la que exterioriza la existencia del derecho real y justifica la tradición" (Boza 1987, p. 59). En el mismo sentido, el Dr. Moisset indica que siendo la propiedad “...un derecho que se manifiesta públicamente entonces por medio del signo externo que regularmente le acompaña y le indica, a saber: El poder y la posesión, Le interesa a la sociedad que las transmisiones se hagan públicas y sé desea saber cuanto contribuye la tradición para obtener ese resultado" (Moisset de Espanés 2004).

17 Antes nos hemos referido a la Teoría de la Doble Causa (teoría del título y el modo). Ver punto 1.2.1 del presente trabajo. 
-que también es causa del cumplimiento de la prestación por el deudor (viejo dueño), entregando la cosa al acreedor; instante en que se va a extinguir la relación obligatoria, quedando cumplida la segunda etapa causal de la transmisión del derecho real, el modo, o tradición.

Concluyendo el citado autor, finalmente dice “... que la tradición es el pago de una obligación preexistente y produce el efecto jurídico de llevar al señorío o poder de hecho del deudor al acreedor, de manera que en ese momento desaparece el primer derecho real y el vínculo obligacional, mientras queda constituido el nuevo derecho real que une al ahora dueño, con la cosa" (Moisset de Espanés año, p. 36).

De otro lado, se ha dicho que para que la tradición logre los efectos del pago (como es la extinción de la obligación nacida del título) no es suficiente la mera concurrencia de ambos elementos: título y modo; ello, a partir del presupuesto en el que "...la tradición no es una mera entrega sino que constituye una entrega cualificada, que tiene por objeto la transferencia de un derecho real. Toda entrega no configura por sí sola tradición; requiere además la intención o animus de transferir y, a su turno, adquirir dominio. La voluntad de las partes determina si la entrega transfiere posesión o propiedad. La entrega deberá estar aparejada de la recíproca voluntad de transferir $\mathrm{y}$, a su turno, adquirir dominio, voluntad esta que se plasma en un acuerdo de transferencia" (Boza 1987, p. 60).

\section{3. ¿Cómo se realiza la tradición?}

Nos hemos referido antes a la "tradición" o "entrega" como objeto o contenido de la obligación (de transferir la propiedad) surgida del contrato de compra-venta; en este sentido, tenemos que tratándose de bienes muebles "la tradición" consistirá en la conducta debida (prestación de dar) en virtud de cuya ejecución se hará efectiva la transferencia de la titularidad del derecho de propiedad de un bien mueble a favor del acreedor (nuevo dueño), quedando cumplida obligación y, en consecuencia, liberado el deudor.
Veamos entonces, cómo se realiza esa "tradición o entrega", para lo cual partiremos señalando que existen dos formas de verificar la tradición: la tradición real y la tradición ficta. Veamos cómo se realizan éstas:

A) La tradición real. Es entendida en general como la entrega material y directa, a través del cual se pone, con ánimo de pago, en poder y posesión del comprador el bien vendido $^{18}$.

B) La tradición ficta. Es aquella forma a través de la cual se considera cumplida o ejecutada la obligación consistente en la entrega material del bien vendido. Describimos a continuación cuáles son esas formas que legalmente suponen la entrega del bien vendido y, en consecuencia, producen el efecto jurídico de la trasferencia de la propiedad de los bienes muebles $^{19}$ :

* La "traditio brevi manu". Es un tipo de tradición ficta que "tiene lugar cuando el adquirente de la cosa la tiene ya en su poder por virtud de otro título, por ejemplo de arrendatario".

* El "constitutum posesorium". Es una forma de tradición ficta que tiene lugar cuando el dueño que enajena entra a poseer la cosa por otro título, como arrendatario, depositario, etcétera.

* La cesión de la acción restitutoria. Esta modalidad de tradición ficta consiste en la cesión del transferente al adquirente del derecho a exigir la restitución del bien al tercero, que es quién lo está poseyendo actualmente.

* La tradición documental o instrumental. Es la modalidad de tradición ficta consistente "en el simbolismo de considerar entregado el bien entregando el documento que lo representa".

* La puesta a disposición. Modalidad de la traditio ficta que tienen por objeto poner al comprador en condiciones de obtener de la cosa el provecho que corresponde al propietario (Borda 1997, p. 193).

18 El artículo 901 del Código civil peruano establece que la tradición "se realiza mediante la entrega del bien a quien debe recibirlo o a la persona designada por él o por la ley y con las formalidades que ésta establece”, entendiéndose esta norma como referida a la tradición real.

19 La definición de los cuatro primeros subtipos de tradición ficta que se anotan, corresponden a Badanes y Torres (1974, 1991). 


\section{LA TRANSFERENCIA DE LA PROPIEDAD EN EL CONTRATO DE COMPRA-VENTA INTERNACIONAL}

1. Regulación normativa de los contratos de compra-venta internacional

Consideramos indispensable referirnos a este aspecto, como punto previo al tema central que nos ocupa, en la medida que dada la nota característica que la compra-venta internacional reviste, como es su carácter de "internacional"20; el mismo que, como ya hemos señalado, supone la posibilidad de la aplicación de más de un derecho interno nacional cuando no de una norma supranacional (como puede ser una convención o tratado) ${ }^{21}$ (Torres Vásquez 1996).

Entonces, en una operación comercial específica de compra-venta internacional de mercaderías (bienes muebles), si partiéramos de un supuesto de conflicto en el que se requiera determinar la titularidad de los bienes -en un momento específico de su traslado del país de origen al país de destino-, tendremos en principio por lo menos dos derechos nacionales de posible aplicación al caso, pudiendo encontrarnos incluso frente a dos soluciones contrapuestas. Si añadiéramos a nuestro supuesto que la regulación de la transferencia de la propiedad se forma, en un caso, con la teoría de la compra-venta real (que supone que la traslación de dominio opera a la sola celebración del contrato) y, en el otro, con la teoría de la compra-venta obligacional, que sostiene que el contrato no es apto per se para producir la traslación del dominio, siendo necesaria además la traditio.

La situación propuesta, sin duda, puede presentarse en la realidad, puesto que cuando nos hemos referido a la naturaleza real u obligacional del contrato hemos encontrado que a nivel del derecho comparado las legislaciones de muchos países han acogido la primera posición y otras tantas, la segunda ${ }^{22}$.

Así, partiendo siempre del supuesto de una situación de conflicto, resulta que la determinación de la norma aplicable a la operación comercial especifica de compra-venta internacional estará acondicionada a varios supuestos; pero, en todo caso, debe tenerse claro que previamente será necesario determinar la jurisdicción (juez competente) que conocerá el caso concreto y que será la encargada de determinar y aplicar dicha norma.

\section{Autonomía de la voluntad de las partes}

Encontramos los siguientes supuestos:

a) Las partes contratantes pueden libremente pactar todas y cada una de las cláusulas o condiciones de la operación comercial que realizan; entonces, es perfectamente posible que éstas prevean expresamente la oportunidad en que se producirá la transferencia de la propiedad de la mercadería (bienes muebles), precisando tiempo o una situación específica.

Este supuesto solo será viable en tanto las partes contrates estén facultadas por sus derechos nacionales a pactar libremente dichas condiciones (principio de libertad contractual $^{23}$.

b) Las partes no precisan en el contrato el momento en que se verificará la traslación de dominio sobre la mercadería, pero en cambio señalan la ley nacional que regula dicho contrato (que puede corresponder a la ley nacional de una de las partes o ser una totalmente ajena). Esta situación también estará sujeta a que esta norma extranjera no sea incompatible con el derecho interno que resulte aplicable ${ }^{24}$.

20 Sobre la determinación de la "internacionalidad" de la compra-venta, ver punto 2.1, ut supra.

21 Nos encontramos en el campo del Derecho Internacional Privado, que «...está integrado por un sistema de normas de colisión o de conflicto (...) encaminadas a determinar la ley aplicable a la solución de conflictos derivados de relaciones jurídicas privadas (civiles, comerciales o de otro tipo) con elementos internacionales relevantes».

22 En el subcapítulo III, punto 2.3.1, ut supra, hemos identificado los países que se acogen a uno u otro sistema, reconociendo efectos reales al contrato o efectos meramente obligacionales, respectivamente.

23 El artículo 1351 del Código Civil peruano, por ejemplo, establece que “... la ley, por consideraciones de orden social, público o ético, podrá imponer reglas o establecer limitaciones al contenido del contrato".

24 El artículo 2049 del Código Civil peruano establece el supuesto de inaplicación de la norma extranjera, señalando que será excluida "...solo cuando su aplicación sea incompatible con el orden público internacional o con las buenas costumbres", en cuyo caso rigen el derecho interno peruano. 
c) Las partes no eligen la ley que regirá el contrato (norma que regulará sus obligación contractuales) en el momento en que se celebra éste y, en su defecto, se rigen por la ley del lugar del cumplimiento de la obligación ${ }^{25}$. La ley aplicable al contrato determina las normas imperativas y los límites de la autonomía de la voluntad de las partes ${ }^{26}$.

Tal como se puede observar, el Código Civil peruano otorga plena libertad a las partes para elegir la ley que regulará el contrato. Éstas pueden elegir la ley del Estado al que pertenecen (nacionalidad), la del Estado en que radican (domicilio), la del Estado en que se celebra o ejecuta el contrato, o la de cualquier otro, aun cuando no tenga vinculación con el contrato. El único requisito es que la ley elegida conste expresamente en el contrato.

En su defecto, si las partes omiten elegir la ley del contrato, éste quedará regulado por la ley del Estado en que se cumplirá la obligación contractual. Si el contrato debe cumplirse en distintos países, éste se regirá por la ley del lugar en que la obligación principal deba ejecutarse y, en el caso de no poder establecer dicho lugar, por la ley del lugar de su celebración.

\section{Norma supranacional (tratado o convención)}

Cuando las partes contratantes pertenezcan a Estados que han suscrito normas supranacionales que regulan la compraventa internacional, en cuyo caso la operación comercial se regulará según las reglas de dicha norma. Sin embargo, cabe indicar que ninguna convención o tratado internacional sobre la materia ha regulado específicamente el tema del perfeccionamiento de la transferencia de la propiedad de los bienes ${ }^{27}$ por lo que dicha cuestión finalmente se resolverá de acuerdo al derecho interno que resulte aplicable.

\section{Normas de derecho interno}

Excluidos los supuestos anteriores, tendremos que en una compra-venta internacional al menos existirán dos derechos internos de posible aplicación, los que serán determinados conforme a las normas de conflicto del derecho internacional privado del Estado a cuya jurisdicción corresponda. Entonces, la determinación del perfeccionamiento de la propiedad dependerá en cada caso de que el derecho interno aplicable haya acogido la teoría que le reconoce efectos reales al contrato o la teoría obligacional del contrato (en este último caso, para que opere dicha transferencia requerirá de la llamada traditio).

5. Transferencia de la propiedad en la compraventa internacional

En la primera parte del presente trabajo nos hemos referido ampliamente al tema de la transferencia de la propiedad en los contratos de compra-venta, en general; ello con la finalidad de establecer a manera de supuestos aspectos doctrinarios básicos y puntuales que -como ya dejamos dicho- consideran de forma plena y totalmente válida a la figura del contrato de compra-venta internacional.

Ahora bien, no obstante que dichos aspectos teóricos y generales puedan coincidir, resulta obvio suponer que cuando la operación jurídico-comercial de compra-venta reviste un carácter internacional, no necesariamente es factible una plena aplicación y verificación de los mismos pues, para aclarar esa inquietud, ha sido la intención de tratar previamente aspectos propios que nos permitieran comprender la naturaleza del contrato de compra-venta internacional.

Finalmente, hemos visto que la determinación de la transferencia de la propiedad en los contratos de compra-venta internacional, dependerá en

25 El artículo 2095 del Código Civil peruano dispone que “... las obligaciones contractuales se rigen por la ley expresamente elegida por las partes y, en su defecto, por la ley del lugar de su cumplimiento. Empero, si deben cumplirse en países distintos, se rigen por la ley de la obligación principal y, en caso de no poder ser determinada ésta, por la ley del lugar de celebración. Si el lugar del cumplimiento no está expresamente determinado o no resulta inequívocamente de la naturaleza de la obligación, se aplica la ley del lugar de celebración".

26 El artículo 2096 del Código Civil peruano dispone que "La ley competente, de conformidad con lo dispuesto en el artículo 2095, determina las normas imperativas aplicables y los límites de la autonomía de la voluntad de las partes".

27 La Convención de Viena de 1980 sobre el contrato de compra-venta internacional de mercancías, considerada como la más amplia regulación de dicha forma contractual, excluye expresamente su aplicación respecto a la transferencia de la propiedad (artículo 4-1-b) al señalar que “... ésta no concierne a los efectos que el contrato puede producir sobre la propiedad de las mercaderías vendidas”. (Pando 1994, p. 653). 
última instancia (si no se reguló por las partes) del derecho interno que le resulte aplicable; es decir, que éste reconozca o no efectos reales al contrato. En el primer caso, no habrá lugar a mayor discusión puesto que bastará con reconocer el momento de la celebración o conclusión del contrato (Langle y Rubio año, p. 139); en el segundo caso, se requeriría saber cuál es el modo de transferencia; es decir, en que momento se dio la tradicio.

\section{La traslación de dominio en la compra-venta internacional}

Consideramos -luego de todo lo tratado hasta aquí- estar en la posibilidad de señalar como premisa general que la sola celebración del contrato de compra-venta internacional, per se, no es traslativo de dominio; así mismo, acogemos como válida y perfectamente aplicable a la compra-venta internacional de mercancías lo sostenido para el derecho común respecto a que la propiedad no solo se trasmite por el simple contrato sino por el contrato unido a la tradición.

Sin embargo, se ha refutado esta posición señalando que la tradición concebida en el derecho civil como la entrega física por parte del vendedor del bien objeto de la venta en favor del comprador no funciona en el comercio internacional, pues en este contrato muchas veces las partes contratantes o sus representantes, si son personas jurídicas, no se llegan conocer en forma directa. Muchas veces el compradorimportador no llega a conocer el producto que ha comprado pues éste generalmente llega a un almacén general de depósito autorizado y en esta condición es vendido al mayorista.

Así Langle y Rubio manifiestan que en el Derecho Mercantil «... no es absolutamente indispensable ese negocio jurídico posterior al contrato de compraventa (la traditio), para que este llene la función que le es propia y característica. La tradición, en sus variadas formas, merece ser estimada solo con el cumplimiento de la obligación de dar posición a la que es nuevo dueño, por haberlo querido así los interesados» (Langle y Rubio año, p. 139).

Para Sierralta «...basta el compromiso claro y manifiesto de las partes para trasladar el dominio de la cosa y exigir el pago, de otra manera estaríamos dando precariedad a los derechos, pues la compra-venta no constituiría un traslado de la propiedad sino una serie de posiciones, es decir situaciones indefinidas en un proceso rápido y continuo donde el contrato se formaliza por un simple telex o llamada telefónica...» (Sierralta año, p. 140).

Sin duda, lo acotado por los autores citados para sostener el carácter real del contrato de compra-venta internacional como suficiente para producir la traslación de dominio de los bienes, solo encuentra justificación al enfrentar los supuestos que implica su carácter internacional (traslación de la mercadería de un estado a otro, por ejemplo) que no concilian en modo alguno con el supuesto de la traditio o "entrega física" (de la mercadería), como modo constitutivo de la trasferencia de la propiedad de bienes muebles.

$Y$ es que, si nos limitamos a identificar la traditio con la "entrega física o material" tendríamos que reconocer que dicha entrega directa por parte del exportador-vendedor al importadorcomprador no es menos que imposible en casi la totalidad de los casos; y, en consecuencia, tendríamos que concluir también que tratándose de compra-venta internacional el solo consentimiento de las partes (conclusión del contrato) produciría el efecto de trasladar la titularidad del derecho de propiedad del vendedor al ámbito del dominio del comprador (quién sería el nuevo propietario apenas se concluya la celebración del contrato).

Sin embargo, éste no es necesariamente el único razonamiento posible, si tenemos en cuenta que la traditio (tradición) es una acepción mucho más amplia que la sola "entrega física" o lo que nosotros hemos llamado Tradición Real ${ }^{28}$. En efecto, ya hemos dejado dicho antes que en el ámbito jurídico, la tradición o "entrega de la cosa" (entendida como el modo de transferir la propiedad) puede verificarse además a través de otras formas o modos, que para el efecto legal buscado (trasferencia de la propiedad) importan la entrega de la cosa. Estaremos entonces ante la llamada "tradición ficta".

Entre los sub tipos de la tradición ficta -que hemos anotado antes ${ }^{29}$ (Sierralta año, p. 139).encontramos a lo que hemos denominado "la

28 Ver el punto sobre la tradición real.

29 Sobre los subtipos de la tradición ficta, ver subcapítulo II, el Punto 2.4.3 - B, ut supra. 
puesta a disposición", describiéndola como aquella modalidad que tienen por objeto poner al comprador en condiciones de obtener de la cosa el provecho que corresponde al propietario.

Finalmente, frente a quienes rechazan la tesis de que la propiedad no se trasmite por el simple contrato sino por éste unido a la tradición, alegando para ello razones de índole prácticocomercial como la siguiente: «..., consideramos que dicha posición no puede explicar el ritmo vertiginoso del comercio internacional en donde muchas veces las partes ni siquiera llegan a conocer la mercancía, menos poseerla ... ${ }^{30}$. Debemos decir que el orden de lo práctico no puede -finalmente- desconocer la naturaleza misma del acto jurídico que se pretende explicar que, en este caso, es precisamente la "naturaleza obligacional" del contrato de compraventa en general (en el segundo subcapítulo hemos abundado sobre el punto); carácter que hemos reconocido para la compra-venta internacional, en la que la tradición o entrega de la mercancía -como transferir la propiedadestará dada por "la puesta a disposición" de la misma en favor del comprador.

\section{Entrega de la mercancía: "la puesta a disposición"}

Salvo que las partes convengan algo distinto o que por el derecho interno aplicable se le reconozca dicho efecto al contrato, hemos reconocido a la tradición o "entrega del bien" como el modo del perfeccionamiento de la transferencia de la propiedad en los contratos de compra-venta internacional de bienes muebles; pero en este caso, hemos reconocido también que frente a la imposibilidad de verificarse una entrega material y directa (tradición real) del vendedor-exportador al comprador-importador, existen otras formas en que dicha entrega de la mercadería se hace efectiva (tradición ficta). En éstas, identificamos un momento preciso en que -para efectos legales- se verifica dicha entrega: la puesta a disposición de la mercadería (entrega ficta).

En la compra-venta internacional, dado que se realiza entre personas que tienen sus establecimientos en distintos países, es un contrato que suele ir acompañado de otros contratos accesorios (Adame 2005, p. 130), pero necesarios para hacer llegar la mercadería al comprador y el pago al vendedor. En cuanto a la identificación de la "puesta a disposición", podemos encontrar una distinción, según se trate de compra-venta que implique transporte de las mercancías o no lo implique.

En el primer caso, la entrega de la mercancía consiste en "ponerlas en poder del primer porteador para que las traslade al comprador". En el segundo, consiste en "ponerlas a disposición del comprador" en un lugar determinado. En realidad, en el caso de mercaderías que se entregan al porteador para que las traslade al comprador, las mercancías que se ponen "en poder" del porteador, se ponen a disposición del comprador, quien podrá recogerlas cuando lleguen a su destino. "Se puede, entonces, concluir que la obligación de entrega consiste en poner las mercancías a disposición del comprador, de modo que éste pueda tomar posesión de ellas (Adame 2005, p.130).

Para poder explicar mejor esta "entrega" mediante "la puesta a disposición" de la mercadería, nos resulta útil la clasificación que hace Eisemann (1985, p. 28) entre compra-venta con entrega directa o compra-venta con entrega indirecta.

La entrega directa es cuando el vendedor entrega las mercancías al mismo comprador, poniéndolas a su disposición en el almacén o fábrica del vendedor, o en algún otro lugar convenido, como un puerto, una frontera o incluso en el propio almacén del comprador.

La entrega indirecta es cuando el vendedor entrega las mercancías a un transportista, quien las recibe a nombre del comprador, sea el transportista elegido y contratado por el vendedor, o por el comprador.

Para Goddard, partiendo de la distinción entre entrega directa e indirecta, y la consideración del transporte que implican, las modalidades del contrato de compra-venta por razón de la entrega, valiéndose de los Incoterm ${ }^{31}$ formula la siguiente clasificación (Adame año, p. 137).

30 «...suele ir acompañada de un contrato de transporte y otro de seguro por riesgos, así como de algún contrato bancario, por ejemplo, una carta de crédito. A veces, ...otros contrato, como fianza...».

31 Son reglas oficiales de la Cámara de Comercio Internacional (XI) que entraron en vigencia el 1 de enero del 2000 para la interpretación de términos comerciales de compra-venta internacional. 


\section{Alcances de la "puesta a disposición de la mercancía”}

El poner las mercancías a disposición del comprador (tradición ficta), de modo que se configure el modo de entrega y perfeccionamiento de la transferencia de la propiedad, exige del vendedor ciertas conductas. Así, nos dice Adame (año, p. 137) que, en primer lugar, se requiere que haya identificado "claramente" las mercancías, ya que de otro modo el comprador no podría saber con seguridad cuáles mercancías son las que están a su disposición.

$\begin{array}{cl} & \text { - En el país del vendedor EXW } \\ \begin{array}{c}\text { Entrega directa } \\ \text { (al comprador) }\end{array} & \text { - En frontera de importación DAF } \\ & \text { - En puerto del comprador DES o DEQ } \\ & \text { - En país del comprador DDU o DDP } \\ & \text { - Por transporte marítimo } \\ & \text { - Contratado por el vendedor CIF o CFR } \\ \text { Entrega } & \text { - Contratado por el comprador FOB } \\ \text { indirecta } & \\ \text { (al transportista) } & \\ & \text { - Por cualquier transporte } \\ & \text { - Contratado por el vendedor CPT o CIP } \\ & \text { - Contratado por el comprador FCA }\end{array}$

En segundo lugar el vendedor en compraventa que no implique el transporte, se requiere que avise al comprador que las mercancías están a su disposición en un lugar determinado, y en compra-venta que implica el transporte, le exige avisar al comprador que las mercancías le han sido despachadas a su nombre o al de la persona que el propio comprador dispusiera, por un determinado medio de transporte y a un cierto lugar de destino, previamente convenidos. Además le exige que proporcione al comprador los documentos o la información necesaria para poder recoger las mercancías.

El mismo autor precisó los casos en que el vendedor no habrá cumplido con su obligación de entregar: "Cuando avisa al comprador que ya puede pasar a recoger las mercancías a un determinado almacén, pero éstas no están todavía claramente identificadas (o especificadas), esto es, contadas, medidas o pesadas (...) Cuando ha puesto las mercancías en poder del porteador, pero no ha avisado de esto al comprador, ni le ha dado la información o documentos necesarios para disponer de ellas en poder del porteador y habiendo avisado al comprador, las envía a una persona o lugar equivocado (Adame año, p. 141).

Queda claro que en estos supuestos, aún cuando aparentemente la mercancía se encuentre a disposición del comprador, no importará la verificación de la "entrega" o "tradición ficta"; en consecuencia, tampoco se producirá el efecto de la traslación de la titularidad del derecho de propiedad de la mercancía, la cual continuará repuntándose dentro del dominio del vendedor-exportador para todo efecto legal que ello importe, como puede ser el de la no liberación de su obligación de transferir la propiedad.

Finalmente, debemos destacar que con el presente trabajo no se ha buscado plantear una novedosa forma o modalidad de la entrega de la mercancía (bienes muebles) en los contratos de compra-venta internacional; más bien se ha buscado analizar el propósito de las modalidades de entrega que son empleadas en la práctica, su acepción jurídica-legal, esto es, identificar su naturaleza jurídica. Así, estamos concluyendo que en los contratos de compraventa internacional la "puesta a disposición" de la mercadería en favor del comprador, equivale a la tradición ${ }^{32}$ (o modo); por ende, producirá inmediatamente el efecto real de la traslación del derecho de propiedad en los bienes que conforman la mercancía.

\section{METODOLOGÍA DE LA INVESTIGACIÓN}

A continuación se indica el tipo de investigación desarrollando, a su vez, el nivel que éste ha tenido para cumplir el objetivo principal y los objetivos específicos señalados al inicio de la misma.

\section{Tipo de investigación}

El estudio dirigido a cumplir el logro del objetivo central de la investigación y los objetivos

32 Tradicio ficta en su modalidad de puesta a disposición. 
específicos es una investigación sustantiva, ello utilizando la clasificación empleada por Sánchez Carlessi y Reyes Meza (2002), ya que se trata de describir y explicar un fenómeno, para entender cómo y en qué momento se perfecciona la transferencia de propiedad en los contratos de compra-venta internacional de bienes muebles determinados.

\section{Nivel de investigación}

El tipo de investigación es sustantiva pues intenta responder un problema teórico de variaciones de un modelo y se orienta a "describir y explicar», lo cual, en cierta forma lo «encamina hacia la investigación básica o pura» (Sanchez y Reyes 2002, p.18-19) haciendo válida la observación siguiente: «Todas las investigaciones básicas pueden ser sustantivas, pero no todas las investigaciones sustantivas, necesariamente son básicas» (p.21). Como quiera que se planteen dos opciones, la descriptiva y la explicativa como "niveles" (p.19) de la investigación sustantiva, y en vista de tener un marco hipotético expresado en un modelo referido a una variable latente, la caracterización se aproxima a la explicación, aunque es conveniente destacar que "... tanto la investigación descriptiva como la explicativa están estrechamente ligadas, ya que no se puede explicar un fenómeno si antes no conocemos sus características" (p.20).

\section{Diseño de investigación}

El diseño empleado es el estudio correspondiente a los no experimentales (Hernández, Fernández y Batista 1999), en su forma de investigación descriptiva (Sánchez Carlessi, y Reyes Meza 2002). Es descriptiva porque identifica, describe y analiza las características de la transferencia de propiedad en los contratos de compra-venta internacional y exploratoria se efectúen normalmente cuando el objeto por examinar es un tema que no ha sido abordado antes, como lo vendrían a ser regulaciones en los tratados internacionales que se han dado por la compra-venta internacional.

\section{Unidad de análisis}

Los tratados internacionales emitidos por sobre el contrato de compra-venta internacional, producidas dentro de la Organización de las
Naciones Unidas en su Comisión de CNUDMI o UNCITRAL, así como las de la UNIDROIT y de la Organización de Estados Americanos (los tratados internacionales sobre la regulación uniforme del contrato de compra-venta internacional) y las normas internas de los países iberoamericanos (España, República Argentina, Ecuador, Chile, Colombia, Venezuela, Bolivia, Brasil, Paraguay) y los países de Alemania, Francia, e Italia.

\section{Población de estudio}

Tratándose de la compra-venta internacional que ha sido materia de regulación uniforme, se analizarán los nueve tratados Internacionales sobre el tema y las normas internas de algunos países como España, República $\mathrm{Ar}$ gentina, Ecuador, Chile, Colombia, Venezuela, Bolivia, Brasil, Paraguay, Alemania, Francia, e Italia.

\section{Tamaño de la muestra}

Se han analizado los nueve tratados y proyecto internacionales sobre la materia que se han concluido hasta la fecha y las normas internas de 13 países más representativos de los sistemas jurídicos Iberoamericanos, alemán, francés e italiano.

\section{Técnicas de recolección de datos}

La principal técnica de la investigación es:

El análisis de contenido. De los 17 tratados que se basa en un estudio de la regulación internacional aplicable a la compra-venta internacional, así como los modos de entrega usados internacionalmente y las normas internas de los países representativos señalados.

El análisis documentario. Se realiza con base en el estudio de lo que han aportado los autores que mayor desarrollo han dado a los temas por investigar, gracias a ello, se tendrá una mayor perspectiva para identificar cuáles son las tendencias de entrega de bienes muebles determinados en la compra-venta internacional. Las fuentes de dicho análisis vendrían a ser el contenido de lo publicado en libros, revistas y actas de los organismos internacionales que han sugerido los tratados internacionales, así como la información brindada a través de Internet. 


\section{ANÁLISIS DE RESULTADOS}

\section{Análisis e interpretación de la información}

Para la recolección de información se recurrió al análisis de los 17 tratados internacionales que regularon la compra-venta internacional y algunos de sus aspectos -dentro de la regulación uniforme y los tratados internacionales-, de las leyes internas que regulan a cada uno de los países escogidos como los iberoamericanos y europeos, así como de las actas que contenían los documentos de elaboración de los tratados y los libros que nos han servido para el desarrollo del marco teórico.

\section{Primero:}

En la compra-venta internacional la obligación de entrega se reputará cumplida e importará el perfeccionamiento de la transferencia de la propiedad de la mercadería (bienes muebles), en el momento que el vendedor-exportador ponga dichas mercancías a disposición del comprador-importador, de modo que éste pueda tomar posesión de ellas.

En la compra-venta internacional, la puesta a disposición de la mercancía (entrega ficta) dependerá que la transacción se haya pactado con transporte de las mercancías o sin éste. En el primer caso, la citada modalidad de entrega de la mercancía se verificará al momento de ponerla en poder del primer porteador para que las traslade. En el segundo, consiste en "ponerlas a disposición del comprador" en un lugar determinado.

Las modalidades de entrega que son empleadas en la práctica nos permiten concluir que en los contratos de compra-venta internacional la "puesta a disposición" de la mercadería en favor del comprador, equivale a la "tradición" (o modo); por ende, producirá inmediatamente el efecto real de la traslación del derecho de propiedad en los bienes que conforman la mercancía.

En la compra-venta internacional el perfeccionamiento de la transferencia de propiedad de los bienes muebles determinados se produce con la puesta a disposición de los bienes muebles materia de contrato por parte del vendedor-exportador al compradorimportador.

\section{Segundo:}

En el derecho comercial internacional, la "tradición" o "entrega del bien" -como el modo del perfeccionamiento de la transferencia de la propiedad- tienen una acepción amplia, superando la idea de la entrega material y directa (tradición real) de la mercancía, y comprendiendo otras formas en que dicha entrega se hará efectiva (tradición ficta). Estas son modalidades en las que se identifica el momento preciso en que -para efectos legales- se importará dicha entrega: la puesta a disposición de la mercadería, tal como hemos podido ver en la parte del marco teórico respectivo

El modo de perfeccionamiento de la propiedad de compra-venta internacional de bienes muebles determinados es la "tradición" que tiene una acepción amplia, superando la idea de la entrega material y directa (tradición real) de la mercancía, que es la "tradicio ficta".

\section{Tercero:}

En las operaciones comerciales de compraventa internacional, la mayoría de los contratos de compra-venta no están reflejados o contenidos en un solo documento (contrato) sino que la operación se refleja a través de diversos documentos como órdenes de entrega télex, pedidos, facturas, etcétera que, por ser numerosos y variados, difícilmente las partes preverán la regulación o determinación del momento de la transferencia de la propiedad.

Dado el carácter obligacional del contrato de compra-venta, deberá reconocer dicho carácter a la compra-venta internacional, estableciendo que para que opere la transmisión de la propiedad de los bienes vendidos no es suficiente el simple contrato sino que requerirá, además, de la tradición.

El contrato de compra-venta es obligacional de tal manera que el título es el contrato mismo y el modo es la tradicio o entrega de bien materia de contrato, perfeccionándose dicha transferencia de propiedad con la tradicio, por lo que no resulta suficiente la sola celebración del contrato que sería el título, debiéndose efectuar el modo que será la tradicio ficta. 


\section{Cuarto:}

El contrato de compra-venta internacional, frente a una situación de conflicto sobre el punto, deberá contener una norma supra nacional si fuera el caso de la adhesión a una Convención o contaremos con más de una norma de derecho interno aplicable y, por ello, más de una posible solución; esto último dependiendo de si el derecho aplicable haya optado para la transferencia de la propiedad: por el solo contrato (contrato real) o si es necesaria además la traditio (contrato obligacional).

La regulación uniforme no regula el efecto real del contrato de compra-venta; es decir, la transferencia de propiedad, por ello se requiere que se regule dicha transferencia de modo expreso porque de no regularse y solo hacerlo como se cumple con la obligación de entrega, seguirá manteniéndose el vacío existente y generará dudas y conflictos para las transacciones comerciales.

Existen diversos tratados internacionales que regulan varios aspectos de la compra-venta internacional, pero ninguno de ellos regula el efecto de la transferencia de propiedad.

\section{Quinto:}

La situación de incertidumbre legal determinará inseguridad en los agentes económicos, entorpeciendo el normal cause del tráfico comercial. También implicará un mayor costo de negociación y transacción, en tanto las partes decidan determinarlo (costo de la información y asesoría).

El derecho internacional privado resulta insuficiente y es inconveniente para solucionar las dificultades de la compra-venta internacional de mercancías, ya que ello siempre desembocará en una aplicación de la ley nacional del país específico que no responderá adecuadamente a la realidad jurídica de las transacciones internacionales, porque su ámbito de regulación es la compra-venta domestica y no está diseñada para la compra-venta internacional.

Consideramos necesaria la existencia de una regulación uniforme de carácter supranacional que establezca la oportunidad en que se verifica la traslación de dominio de las mercancías (bienes muebles), del ámbito del exportador-vendedor al ámbito de importador-comprador.

Tratándose de los contratos de compra-venta internacional, resulta necesario una regulación uniforme sobre la transferencia de la propiedad a través de un tratado para terminar con la incertidumbre legal.

\section{CONCLUSIONES}

1. En la compra-venta internacional la obligación de entrega es cumplida e importará el perfeccionamiento de la transferencia de la propiedad de los bienes muebles determinados, en el momento que el vendedor-exportador ponga dichas mercancías a disposición del comprador-importador, de modo que éste pueda tomar posesión de ellas.

2. En el derecho comercial internacional la "traditio" o "entrega del bien" -como el modo del perfeccionamiento de la transferencia de la propiedad- tienen una acepción amplia, superando la idea de la entrega material y directa (tradición real) de la mercancía, comprendiendo otra forma en que dicha entrega se hará efectiva (tradición ficta), siendo que la puesta a disposición de la mercancía /entrega ficta dependerá que la transacción se haya pactado con transporte de las mercancías o sin éste. En primer caso, la citada modalidad verificará la mercancía al momento de ponerlas en poder del primero porteador para que las traslade. En el segundo, consiste en "ponerlas a disposición del comprador", en un lugar determinado.

3. Dado el carácter obligacional del contrato de compra-venta, deberá reconocerse dicho carácter también a la compra-internacional, estableciéndose para ello que para que opere la transmisión de la propiedad de los bienes vendidos no es suficiente el simple contrato sino que requerirá además de la tradición.

4. En todos los tratados sobre la materia no se ha dado una regulación uniforme respecto a la transferencia de la propiedad dentro de los contratos de compra-venta internacional, habiéndose incluso excluido de manera expresa la regulación de dicho efecto en el Convenio de Viena de 1980. 
5. Es necesario una regulación uniforme sobre la transferencia de la propiedad en un tratado, para terminar con la situación de incertidumbre legal que genera conflictos e implica costos adicionales a las negociaciones comerciales internacionales.

\section{LITERATURA CITADA}

Adame Goddard, Jorge. (2005). El contrato de compra-venta internacional. McGraw-Hill y Universidad Nacional Autónoma de México, México.

Alcóver Garau, Guillermo. (1991). La transmisión del riesgo en la compra-venta mercantil. Editorial Civitas S.A, Ciudad.

Badanes Gasset, Ramón y Torres Mendez, Miguel. (1979). El contrato de compra-venta. Tomo I. Librería Ramón Bosch, Barcelona. Citados por Escobar Rozas, Fredy. (1992). "En el Código civil peruano, ¿es el contrato de compraventa el que transfiere la propiedad mueble?". Fondo Editorial de la Pontificia Universidad la Católica del Perú, Lima, pp. 75-76.

Balestra, Ricardo. (1997). Derecho Internacional Privado, Parte Especial. Abeledo Perrot, Buenos Aires.

Barchi Velaochaga, Luciano. (1992). "La transferencia de la titularidad de la propiedad: a propósito del Código Civil Peruano". En: Revista Jurídica del Ministerio Público. Editorial, Lima.

Bescos Torres, Modesto. (1993). Contratos internacionales. ICEX, Madrid.

Bigio Chrem, Jack. (1988). "La compra-venta y la transmisión de propiedad". En: Fernández Cruz, Gastón. (1994). Para leer el Código Civil. Vol. I. Fondo Editorial de la PUCP, Lima.

Boggiano, Antonio. (2011). Contratos Internacionales. Ediciones Depalma, Buenos Aires.

Borda, Guillermo A. (1997). Manual de Contratos. Octava Edición. Editorial Perrot, Buenos Aires.

Boza Dibós, Beatriz. (1986). "La tradición: elemento necesario y suficiente para la transferencia de los bienes no registrables". En: Thémis, Revista de Derecho. Segunda Época, $\mathrm{N}^{\circ}$ 4. Editorial, Lima.
Boza Dibós, Beatriz. (1987). “Sistema de Transferencia adoptado por el Legislador Peruano de 1984 (un comentario al artículo 947 del Código Civil". En: Thémis, Revista de Derecho. Segunda Época, No 6 . Editorial, Lima. Código Civil de la República Argentina.

Código Civil Peruano.

Constitución Política del Perú.

De La Puente y Lavalle, Manuel. (1995). "El contrato con efectos reales". En: Ius et Veritas. Año V, No 8. Asociación Civil lus Et Veritas, Lima.

Decreto Supremo No 011-99-RE, Aprueba adhesión del Perú a la "Convención de las Naciones Unidas sobre los Contratos de Compraventa Internacional de Mercaderías"

Eisemann, F. (1985). Incoterms. Banco de Comercio Exterior, Madrid; citado por Adame Goddard, Jorge. (2005). El contrato de compra-venta internacional. MacGraw-Hill y Universidad Nacional Autónoma de México, México.

Fernandez Cruz, Gastón. (1994). "La obligación de enajenar y el sistema de transferencia de la propiedad inmueble en el Perú". En: Thémis, Revista de Derecho. Segunda Época, $N^{\circ} 30$. Editorial, Lima.

Flores Forno, Hugo. (1994). "El contrato con efectos reales". En: Ius et Veritas. Año IV, № 7 . Asociación Civil lus Et Veritas, Lima.

Hernández, Fernández y Batista. (2006). Metodología de la Investigación, Cuarta edición, McGraw-Hill Interamericana, México.

Langle y Rubio, Emilio. (1950). "Manual de Derecho Mercantil”. En: Sierralta Ríos, Aníbal. (2007). Los contratos de Comercio Internacional. Editorial PUCP, Lima.

Moisset de Españes, Luis. (2004). "La Tradición Traslativa del Dominio". En: Revista de Derecho Privado (2004). Curso de Obligaciones. Ed. Astrea, Córdova.

Pando Vílchez, Jorge. (1994). "Compra-venta internacional de mercaderías: hacia una regulación uniforme". I Congreso Nacional de Derecho Civil y Comercial. UNMSM, Lima.

Puig Brutau, José. (1994). Fundamentos de derecho civil. Ed. Bosch, Barcelona. 
Sánchez Carlessi y Reyes Meza. (2002). Metodología y diseño de la investigación científica. Universidad Ricardo Palma, Lima.

Sierralta Ríos, Aníbal. (2007). Los contratos de Comercio Internacional. Editorial PUCP, Lima.

Torres Méndez, Miguel. (1991). "La transferencia de propiedad de los bienes muebles incorporales en el código civil". En: Revista de derecho de la PUCP. № 45, Diciembre 1991.

Torres Vásquez, Aníbal. (1996). Código Civil. Tercera edición. Editorial, Lima.
Constitución Política del Perú.

Decreto Supremo № 011-99-RE, Aprueba adhesión del Perú a la "Convención de las Naciones Unidas sobre los Contratos de Compraventa Internacional de Mercaderías"

Convención de las Naciones Unidas sobre los Contratos de Compra Venta Internacional de Mercaderías.

- WWW. UNCITRAL

- WWW. UNIDROIT 